Research Article

Ulrike Brokmann*, Tobias Milde, Edda Rädlein, and Klaus Liefeith

\title{
Fabrication of 3D microchannels for tissue engineering in photosensitive glass using NIR femtosecond laser radiation
}

https://doi.org/10.1515/bglass-2019-0003

Received May 04, 2018; revised ??; accepted Jan 03, 2019

Abstract: The biocompatibility of photosensitive glasses allows various biomedical applications; one is the field of tissue engineering and more precisely microengineered tissue-on-a-chip platforms to study the tissue microenvironment and disease modelling. Three dimensional architectures of adapted components are required for modern materials. A photosensitive lithiumalumosilicate glass FS21 was investigated regarding the interaction with a Ti:Sapphire laser system to build three dimensional buried channels inside the glass. Femtosecond laser radiation with a wavelength of $800 \mathrm{~nm}$ and pulse duration of 140 fs was used to modify the glass structure. Subsurface channel geometries were achieved by a subsequent thermal treatment and were formed into capillaries using wet chemical etching of the exposed and crystallised channels. Contrary to ultraviolet (UV) exposure, spectral optical investigations showed that fs laser exposure caused various radiation induced defects in the base glass coupled with the generation of photoelectrons for the photochemical modification of silver ions. We observed an outgassing of different species coming from raw materials of the original glass batch during the glass crystallisation process. Etch rate ratios differ between 1:25 and 1:45 and are dependent on: stoichiometric deviation between surface and bulk, crystal size and distribution and exchange of the etching agent in narrow capillaries.

Keywords: photosensitive glass, fs laser exposure, 3D machining, tissue engineering

\section{Introduction}

Femtosecond (fs) laser irradiation of photosensitive glasses enables the three dimensional (3D) microstructuring of glass for microfluidic, microoptic and micromechanic systems [1-4]. These glasses are suitable materials i.e. for tissue engineering applications due to their excellent biocompatibility [5, 6]. Figure 1 gives an example for the connection of mouse fibroblasts on the surface of a microstructured photosensitive glass device. The figure shows the etched surface (by diluted HF) of a glass ceramic that formed after the glass experienced UV exposure followed by thermal treatment. No cell damaging effects were found. In the current study, a cell vitality of $93 \%$ was found on surfaces from all processing stages.

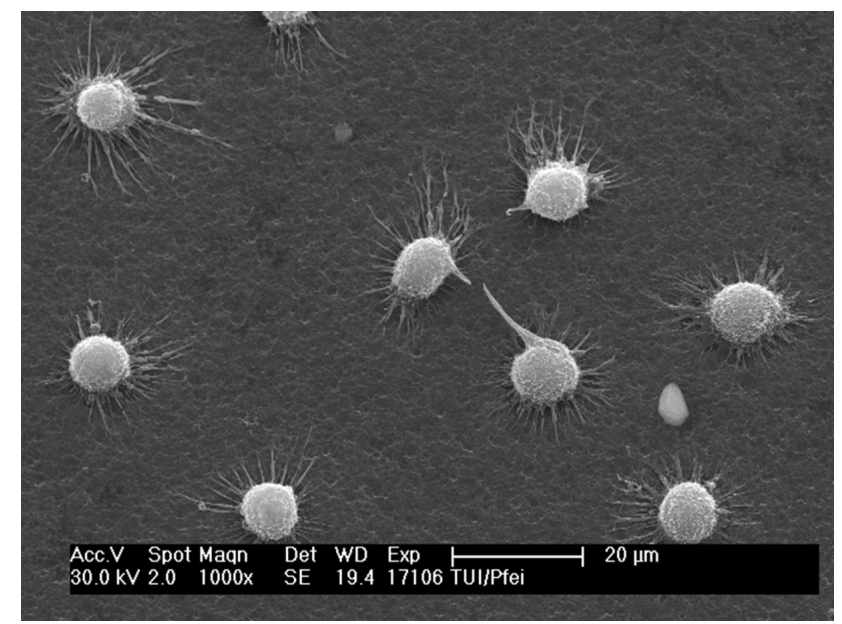

Figure 1: Cell-line: L929 (mouse fibroblasts of the connective tissue) on the surface of modified FS21 after wet chemical etching with diluted HF. The lithium metasilicate containing glass ceramic was obtained after UV exposure and thermal treatment.

The photoform process, which can be used for the fabrication of such components, involves in the first step the irradiation with UV light or short pulse laser radiation, in a second step the crystallisation of lithium metasilicate in laser exposed areas during a thermal treatment and in

\footnotetext{
*Corresponding Author: Ulrike Brokmann: TU Ilmenau Ilmenau, Germany; Email: ulrike.brokmann@tu-ilmenau.de

Tobias Milde, Klaus Liefeith: Institute of Bioprocessing and Analytical Measurement Techniques Heiligenstadt, Germany Edda Rädlein: TU Ilmenau, Germany
} 
the third step the dissolution of these crystalline areas using diluted hydrofluoric acid. The size and the distribution of lithium metasilicate crystals are important for the size of geometrical features that can be achieved. Furthermore the surfaces roughness inside holes (narrow capillaries) will be influenced significantly. It is possible to control geometrical resolution and roughness not only during a well-defined thermal treatment. The photochemical modification of photosensitive glasses is dependent on photon energy and threshold energy densities. That means that the exposure step is also suitable for the design of a process optimised crystalline structure $[7,8]$. Compositions of available photosensitive glasses are optimised for a broad band UV lamp exposure. For that case the current state of the knowledge for electron transfer interprets of the photochemical reaction as followed:

$$
\begin{gathered}
\mathrm{Ce}^{3+}+h v \rightarrow\left(\mathrm{Ce}^{3+}\right)^{+}+e^{-} \\
\mathrm{Ag}^{+}+e^{-} \longrightarrow\left(\mathrm{Ag}^{+}\right)^{-}
\end{gathered}
$$

This process is well investigated $[9,10]$ and important for mask-based lithography processes.

The advantage of fs laser exposure over the exposure with broad band UV light is the application of well-defined and locally focused energy densities. Therefore, it is possible to improve the geometrical resolution by direct writing with a small, tuned focus and to obtain increased etch rate ratios to fabricate 3D embedded geometries even with movable parts of the components [11]. Although several techniques are described to develop innovative applications, the interaction between fs laser radiation with a photosensitive glass is not yet sufficiently understood. A high number of publications provides specific information about radiation induced defects and changes in the glass structure. In the following, some facts relevant for the current study are briefly summarized. The discussion of laser assisted interaction processes dealt with photochemical, photothermal effects and a combination of both. The influence of cw NIR laser irradiation on the thermal induced crystallization of lithium disilicate in base glasses with variable $\mathrm{CuO}$ contents is discussed in [12]. Critical crystal growth rates have been determined, they correspond with thermal treatments in an electrical furnace. That means cw NIR laser absorption leads to increased temperatures in exposed areas usable for crystallization processes and secondly low temperatures at high scan velocities lead to structural changes regarding the change of the optical index. Structural changes in the form defect centres with increased discrete optical absorptions are dependent from the chemical composition of the glass and stoichiometric discrepancies. An overview on intrinsic defects (Frenkel defects) at bridging and non-bridging oxygen atoms in silicate glass is given in [13]. The E'center and peroxy radical are discussed as the best known radiation induced defect centres in consideration of variable contents of $\mathrm{OH}$ groups, alkali contents and impurities. Bellec et al. [14] discussed the fs laser induced clustering coupled with a thermal diffusion to the border of the focus and dissolution processes in the focus centre. In addition to reactions (1) and (2) intensive radiation can induce further reactions inside the glass structure by breaking bonds in the base glass composition [15]. In these cases, the photoionisation of $\mathrm{Ce}^{3+}$ should only be considered as a minor process in the generation of photoelectrons.

Furthermore it has been reported that high aspect ratios up to 1:50 of etched microstructures can be achieved if the local concentration of photoelectrons can be increased to generate a large number of silver nuclei for a high content of crystalline lithium metasilicate [16-18]. We investigated the interaction of a photosensitive glass with fs laser radiation for the utilisation in tissue engineering applications, like microengineered tissue-on-a-chip platforms for $3 \mathrm{D}$ cell cultivation or fluidic chambers with interconnecting channels. Therefore it is necessary to study the following process steps: irradiation treatment of the glass, thermal treatment for glass crystallization by growing lithium metasilicate in exposed areas and wet chemical etching of crystallised parts using diluted hydrofluoric acid dependent on parameter variations in the exposure process.

\section{Material and experimental procedures}

A photosensitive lithiumalumosilicate glass (FS21) with the chemical composition (mol\%) of $69.5 \mathrm{SiO}_{2}-22.0 \mathrm{LiO}_{2}$ $-2.3 \mathrm{Na}_{2} \mathrm{O}-2.3 \mathrm{~K}_{2} \mathrm{O}-3.9 \mathrm{Al}_{2} \mathrm{O}_{3}$ was used. The photosensitivity is achieved by an additional doping (mol\%) with $0.2 \mathrm{Ag}_{2} \mathrm{O}, 0.3 \mathrm{Sb}_{2} \mathrm{O}_{3}, 0.1 \mathrm{SnO}$ and $0.04 \mathrm{CeO}_{2}$. Glass semiproducts in form of flat plates with $100 \mathrm{~mm}$ in diameter were fabricated as a result of an industrial melting process based on oxides, carbonates and nitrates as raw materials. A press forming tool was used, followed by a defined annealing and a final grinding and polishing procedure to a variety of thicknesses between $0.3 \mathrm{~mm}$ and $2 \mathrm{~mm}$ [9]. These glass plates possess a surface roughness of $\mathrm{Ra}<9$ $\mathrm{nm}$. Plane parallelism is given within a tolerance band of $0.003 \mathrm{~mm}$ at $\varnothing 100 \mathrm{~mm}$. All samples used in this work have a thickness of $0.5 \mathrm{~mm}$ and were cut into pieces of $10 \times 15$ $\mathrm{mm}^{2}$. 
Femtosecond laser exposure experiments were carried out using a Ti:Sapphire laser system "Vision2" (Coherent). For all experiments a constant wavelength of $\lambda=800 \mathrm{~nm}$ with a pulse duration of $\tau=140$ fs and a repetition rate of $80 \mathrm{MHz}$ was used without additional amplification. The beam with focus diameter of $4 \mu \mathrm{m}$ is nearly Gaussian and was focused by an oil immersion objective with high numerical aperture of $\mathrm{NA}=1.4$. In order to manufacture 3D structures, the samples were placed on a motorized air bearing three-axis translation stage below the objective. The beam was electrically switched by an acousto-optic modulator to determine the number of photons involved in the photoform process of FS21. Therefore a series of spots was set with $1 \leq \mathrm{N} \leq 2000$ pulses at pulse energies of $0.2 n J \leq E \leq 3 n J$. Laser exposure experiments were carried out to follow two main strategies. At first, we determined a field of relevant process parameters to investigate the radiation interaction with the photosensitive glass. Based on these results we realised first subsurface 3D fluidic channel geometries using fs laser exposure. In both cases it was necessary to write suitable geometries directly in the volume of the photosensitive glass, consisting of defined arranged pulse series. Single spot exposure experiments were used for the determination of the critical dose to modify the glass structure for the silver cluster growth, followed by lithium metasilicate crystallisation. Lines of pulse sequences were generated by variation of the scan speed in the range of $5 \mathrm{~mm} / \mathrm{s} \leq \mathrm{v} \leq 35 \mathrm{~mm} / \mathrm{s}$ in $\mathrm{x}, \mathrm{y}, \mathrm{z}$ direction. The connection of lines to more complex geometries (channels, chambers or planes) required a variation of the distances between two neighbouring lines in the range $4 \mu \mathrm{m} \leq \mathrm{y}, \mathrm{z} \leq 7.5 \mu \mathrm{m}$. Therefore a stereo lithography (stl) model was designed to drive the laser system.

For comparison, UV light exposure experiments were performed using a mask aligner MA56 (Süss) with a broad band high-pressure mercury lamp and an adapted optical imaging system specified for a radiation with a constant energy density of $\epsilon=60 \mathrm{~J} / \mathrm{cm}^{2}$. In the photoform process this value results in an etch rate ratio of 1:25.

Thermal treatment of the exposed samples occurred on horizontally placed ceramic plates in a muffle furnace. A one step program at $\mathrm{T}=570^{\circ} \mathrm{C}$ for $\mathrm{t}=1 \mathrm{~h}$ was used due to a sufficient overlap of the temperature ranges for heterogeneous nucleation and crystal growth [9]. All samples were placed inside a muffle furnace and later removed from the furnace while at the maximum temperature.

Wet chemical etching experiments were carried out at room temperature using hydrofluoric acid with a concentration of $5 \%$ and under ultrasonic support.

Fs laser radiated samples as well as UV light exposed samples were investigated by UV-VIS spectroscopy before thermal treatment. A spectral photometer Jasco V-570 with an integrating sphere ISN-470 was used. The photometer is specified in the wavelength range $190 \mathrm{~nm} \leq \lambda \leq 2500 \mathrm{~nm}$ and the integrating sphere in the range $220 \mathrm{~nm} \leq \lambda \leq 2000$ $\mathrm{nm}$. The glass samples (backside covered with a $\mathrm{BaSO}_{4}$ coated plate) were mounted as a part of the integrating sphere. Light source and detector (shaded, positioned to one another with an angle of $45^{\circ}$ ) are situated on the same side opposite to the sample. In this arrangement the sample changes the reflection degree of the integrating sphere and the detected intensity depends on the sample thickness. Absorption spectra in form of optical density o.D = $-\log \left(\mathrm{I} / \mathrm{I}_{0}\right)$ were measured in a wavelength range $200 \mathrm{~nm} \leq$ $\lambda \leq 500 \mathrm{~nm}$ for the investigation of near surface radiated glass and the analysis of effects in the range of the absorption edge of the photosensitive glass. We point out that the measured values for $\lambda<220 \mathrm{~nm}$ are not explicitly specified for the used model of integrating sphere. This fact has no relevance for discussion in this wavelength range. Figure 2 shows the optical density (o.D.) in the untreated state of the glass before any exposure.

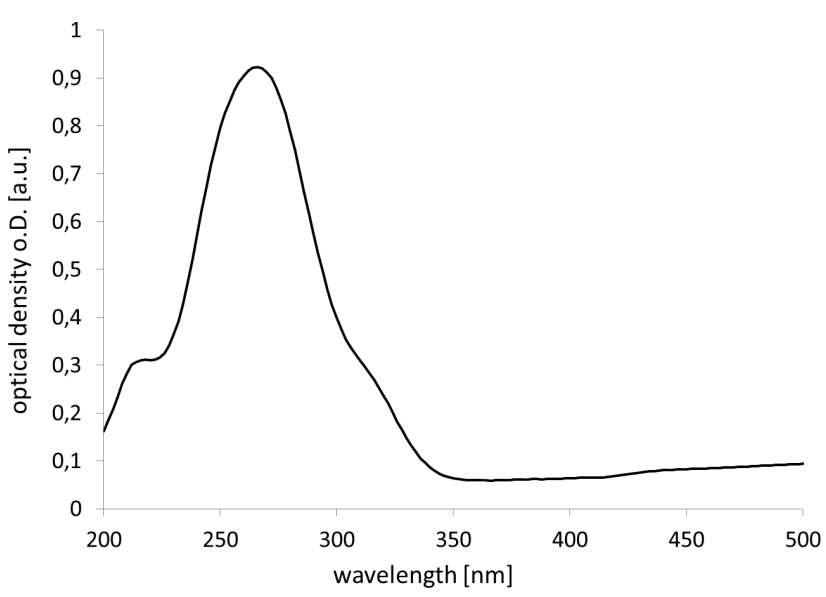

Figure 2: Wavelength dependent optical density (o.D.) of an unexposed photosensitive glass FS21.

The wavelength range of $250 \mathrm{~nm} \leq \lambda \leq 350 \mathrm{~nm}$ represents the transition from high absorption to high transmission at the absorption edge. The global maximum at $\lambda=264 \mathrm{~nm}$ corresponds with the cut-off wavelength, determined using transmission measurement in a two beam spectrophotometer. The absorption edge of the silicate glass overlaps with the absorption band of $\mathrm{Ce}^{3+}$ at $\lambda=310$ $\mathrm{nm}$ [9]. For regions of high absorptions at $\lambda<250 \mathrm{~nm}$, the reflection itself can be used to determine absorption bands because the imaginary component of the index of refraction becomes an appreciable fraction of unity. The conclusion is that the reflectance is high in case of large absorp- 


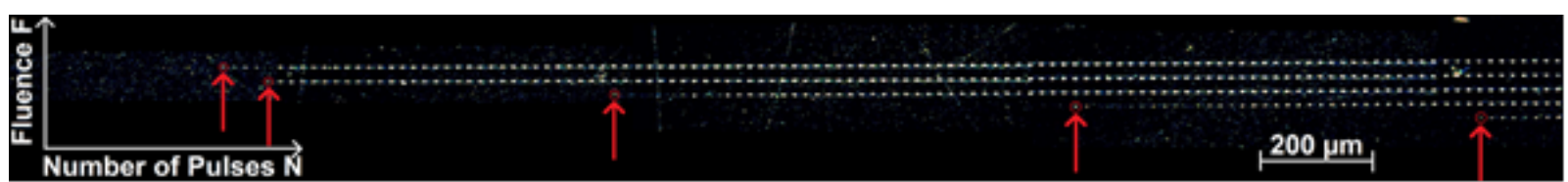

Figure 3: SEM image of FS21: The evolution of a series of irradiated spots with different numbers of pulses after etching. The number of pulses per spot is rising from the left to the right and the fluence is reduced from the top to the bottom. Red marks correspond to threshold fluence $\mathrm{F}_{t h}$.

tion [19]. However, the reflection signal is additionally coupled to the interaction of the interfaces and refractive index transitions. A comparison with the literature leads to the assumption that ion related absorption energies with an absorption band at $\lambda=220 \mathrm{~nm}$ correspond with a superposition of discrete absorptions of $\mathrm{Ag}^{+}, \mathrm{Sb}^{3+}, \mathrm{Sn}^{2+}$ ions [20] as well as peroxide groups (POR) [21, 22]. [23] states that $\mathrm{Ce}^{3+}$ ions causes absorption at $\lambda=220 \mathrm{~nm}$ in a fluorid phosphate glass.

The documentation of the distribution of crystallised areas after the thermal treatment and the etch depth in capillaries after the etching procedure is based on optical microscopy analysis using a Axiotech (Zeiss) and a SEM Hitachi S-4800. The content of gas bubbles was analysed by means of mass spectroscopy (Gas Inclusion Analyzer 522, InProcess Instruments).

\section{Results}

\subsection{Determination of the critical dose and the number of photons involved in the fs laser exposure process}

Similar to numerous investigations of the photoform process regarding the commercial photosensitive glass Foturan [16, 24-26], an established spectrum of methods was applied to evaluate the photoreaction mechanism of the fs laser exposure using the wavelength of $800 \mathrm{~nm}$. A series of irradiated spots with different numbers of pulses was investigated. Figure 3 shows the SEM image of the spot evolution after thermal treatment and wet chemical etching. Figure 4 represents the typical log-log plot of the fluence threshold dependent on the number of pulses. Data published in [24] indicate a direct relation between the irradiation dose $\mathrm{D}$ and the density of crystallite nuclei formed owing to a multiphoton absorption process. This dose parameter was defined as

$$
D=N \cdot F^{m}
$$

where $F$ is the fluence, $\mathrm{N}$ is the number of pulses and $\mathrm{m}$ is the number of photons involved in the absorption process
[24]. It is assumed that there is a proportionality between the density of crystallite nuclei and the amount of reduced $\mathrm{Ag}^{0}$, which is likewise proportional to the probability of photon absorption whereas the probability of photon absorption depends on $F^{m}$. If the probability is multiplied by the accumulation, in this case the number of photons, the result represents the dose.

Successful wet chemical etching occurs only if a critical density of crystallite nuclei is reached. This critical density is associated with the critical dose $D_{c}$ that has to be exceeded to initiate laser induced phase transformation. By establishing $D_{c}$ the fluence $F$ is transferred to a so-called threshold fluence $F_{t h}$ :

$$
F_{t h}=D_{c}^{\frac{1}{m}} \cdot N^{-\frac{1}{m}}
$$

As expected from equation (4) the log-log plot (Figure 4) shows a linear proportionality between the fluence threshold $\mathrm{F}_{t h}$ and the number of pulses $\mathrm{N}$. The number of involved photons $m$ that define the critical dose $D_{c}$, is given by the gradient of the regression line. This definition of dose is unusual and has a unit that depends on $\mathrm{m}$. It takes into account relaxations during nucleation and crystal growth processes and wet chemical etching. Moreover, it quantifies the complex short pulse laser induced absorption process that leads to a photochemical modification with a subsequent lithium metasilicate crystallisation. The results are specified as $\mathrm{m}=4$ and $D_{c} \approx 7.6 \cdot 10^{-6}$ $\left(\mathrm{J} / \mathrm{cm}^{2}\right)^{4}$. According to [24] this means that in an average FS21 experiment at $800 \mathrm{~nm}$ a four photon process is needed for the reduction of one silver ion. Collectively a dose of about $7.6 \cdot 10^{-6}\left(\mathrm{~J} / \mathrm{cm}^{2}\right)^{4}$ has to be exceeded. The value of $m=4$ is twice as large as the $m=2$ measured in the case of the pulsed UV laser investigation on Foturan [24] but lower than reported in studies with comparable wavelengths where $m=6[17,27]$. Also, the critical dose is lower than in comparable experiments. Thus, FS21 seems to need less energy input for the initiation of the necessary photochemical reactions than Foturan under comparable circumstances.

Recently published studies based on Foturan have shown that the photoform procedure of photosensitive glass involves a multiphoton process depending on wave- 


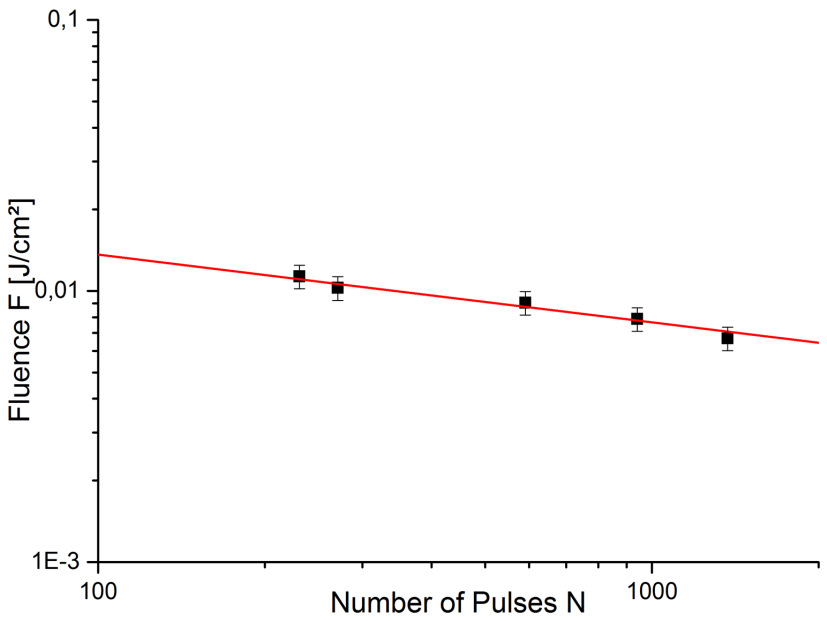

Figure 4: Log-log plot of the fluence threshold versus a variation of the number of pulses for the laser radiation at $800 \mathrm{~nm}$. The necessary number of photons and the critical dose are determined as $\mathrm{m}=4$ and $\mathrm{D}_{c}=7.6 \cdot 10^{-6}\left(\mathrm{~J} / \mathrm{cm}^{2}\right)^{4}$.

length and pulse durations [16, 24, 25]. It was found that for a nanosecond laser at $355 \mathrm{~nm}$ two photons are involved in the process $[24,26]$ and in case of a femtosecond infrared laser working at $1027 \mathrm{~nm}$ up to 8 photons are involved [16, 25, 26]. In wavelength regions similar to the irradiation in this study, 6 photons were found. An overview of those parameters is displayed in Table 1 :

Table 1: Overview of former works regarding the laser wavelength, critical dose and number of involved photons with glass similar to FS21.

\begin{tabular}{lcccc}
\hline Glass & $\begin{array}{c}\text { Wavelength } \\
{[\mathrm{nm}]}\end{array}$ & $\begin{array}{c}\text { Crit. } \\
\text { Dose } \\
{\left[/ \mathrm{cm}^{2}\right]^{m}}\end{array}$ & $\begin{array}{c}\text { Number of } \\
\text { photons }\end{array}$ & Reference \\
\hline Foturan & 355 & $9.0 \cdot 10^{-6}$ & 2 & {$[14]$} \\
Foturan & 775 & $1.3 \cdot 10^{-5}$ & 6 & {$[17]$} \\
Foturan & 800 & $1.2 \cdot 10^{-2}$ & 6 & {$[9]$} \\
FS21 & 800 & $7.6 \cdot 10^{-6}$ & 4 & This study \\
Foturan & 1027 & $2.0^{\star} 10^{-6}$ & 8 & {$[16]$} \\
\hline
\end{tabular}

Due to the optimisation of the laser scanning process for the generation of different geometries with a high accuracy of size, experiments with a significantly increased radiation dose by a factor of $4 \cdot 10^{3} \times D_{c}$ were employed.

\subsection{UV-VIS spectroscopy after exposure process}

According to the Kubelka-Munk theory, which describes light absorption and scattering properties of layers [28], we used reflection measurements to calculate the relative change in absorption of exposed glasses in a thin surface layer in comparison to an unexposed glass. The KubelkaMunk function is valid (i) if the absorption of the investigated species is well separated from the absorption of other species and (ii) the species exist in a high dilution. Both conditions are partially fulfilled in case of the radiation induced ionisation of dopants and additional defect centers inside an exposed photosensitive glass. Such defects are described as electron center (EC) and hole center (HC) [13]. As described earlier, defects are distinguished according to their origin. Intrinsic defects form in glass matrix itself, often as radicals on the network former, while extrinsic defects are caused by dopants or impurities (often as photoionization of polyvalent ions) [29]. Table 2 gives an overview on absorption wavelengths of ion species which are important for a discussion of radiation induced effects in photosensitive glasses. This overview documents the importance of the chemical composition of glasses for the determination of precise values, due to the fact that the ion environment influences the absorption energy. Furthermore there are several overlaps of absorption bands, i.e. for dopants like $\mathrm{Sn}^{2+}, \mathrm{Sb}^{3+}, \mathrm{Ag}^{+}$. This makes a discussion of radiation induced effects related to these ions rather difficult.

Figure 5 shows a direct comparison of radiation induced absorption of a FS21 sample exposed with fs laser exposed and with a mask aligner. It has to be noticed that the used energy density for the mask aligner exposure is with $\epsilon=60 \mathrm{~J} / \mathrm{cm}^{2}$ higher than those of the fs laser exposure with $\epsilon=0.03 \mathrm{~J} / \mathrm{cm}^{2}$ per pulse (number of pulses $\mathrm{N}_{\text {eff }}=230$ ). Both curve progressions show three characteristic peaks with differences in peak positions and peak sizes. The overlap of induced absorption bands coupled with a band shift of the absorption edge makes an allocation of peaks in the wavelength range of $200 \mathrm{~nm}<\lambda<320 \mathrm{~nm}$ rather difficult. Peaks in this wavelength range result from the calculation $\Delta$ o.D./o.D. $=\left(\right.$ o.D.exposed ${ }^{-0 . D}$.unexposed $) / o . D \cdot$.unexposed as a consequence of changes in the inflection points of the original measurements and cannot be allocated to discrete species.

With regard to Table 2 it seems to be possible that any irradiation of photosensitive glass leads to increased absorptions in the range $<320 \mathrm{~nm}$ caused by positive charged hole centers (HC), like oxygen hole centers (OHC), non bridging oxygen hole centers (NBOHC), or negative 
Table 2: Overview about absorption wavelengths of various ion species in different glass types.

\begin{tabular}{|c|c|c|c|}
\hline Species & $\begin{array}{l}\text { Wavelength of } \\
\text { absorption [nm] }\end{array}$ & Reference glass & Reference \\
\hline \multicolumn{4}{|c|}{ Ions (related as dopants for photosensitivity in FS21) within a untreated glass structure } \\
\hline \multirow[t]{3}{*}{$\mathrm{Ce}^{3+}$} & 305 & Photo-Thermo-Refractive glass & [31] \\
\hline & 310 & Lithiumalumosilicate glass & [32] \\
\hline & 323 & Photo-Thermo-Refractive glass & {$[20]$} \\
\hline $\mathrm{Ce}^{4+}$ & 240 & Photo-Thermo-Refractive glass & [31] \\
\hline \multirow[t]{5}{*}{$\mathrm{Ag}^{+}$} & 192 & Sodiumborate glass & [33] \\
\hline & 208 & Sodiumborate glass & [33] \\
\hline & 220 & Fluoridphosphate glass & [34] \\
\hline & 220 & Photo-Thermo-Refractive glass & [31] \\
\hline & 237 & Photo-Thermo-Refractive glass & [35] \\
\hline $\mathrm{Ag}^{ \pm 0}$ & 345 & Soda lime glass & {$[21]$} \\
\hline \multirow[t]{2}{*}{$\mathrm{Sn}^{2+}$} & 206 & Duran & [35] \\
\hline & 237 & PTR glass & {$[20]$} \\
\hline $\mathrm{Sn}^{4+}$ & 180 & Duran & [35] \\
\hline \multirow[t]{4}{*}{$\mathrm{Sb}^{3+}$} & 217 & Borosilicate glass & [36] \\
\hline & 237 & Photo-Thermo-Refractive glass & [20] \\
\hline & 240 & Photo-Thermo-Refractive glass & [31] \\
\hline & 250 & Metaphosphate glass & [34] \\
\hline \multicolumn{4}{|c|}{ Intrinsic defects - hole center $(\mathrm{HC})$} \\
\hline \multirow[t]{2}{*}{$\mathrm{HC}$} & 200 & BK7 & {$[40]$} \\
\hline & & DURAN & \\
\hline \multirow[t]{2}{*}{$\mathrm{OHC}$} & 305 & BK7 & {$[40]$} \\
\hline & 310 & DURAN & \\
\hline \multirow[t]{2}{*}{$\mathrm{NBOHC}$} & 257 & Fused silica & [63] \\
\hline & $445-630$ & Soda lime glass & [21] \\
\hline \multicolumn{4}{|l|}{ Si NBOHC } \\
\hline $\mathrm{H}_{I}$ & 440 & BK7 & [40] \\
\hline $\mathrm{H}_{I I}$ & 620 & & \\
\hline$\left[\mathrm{AlO}_{4} / \mathrm{M}^{+}\right]^{+}$ & 620 & Soda lime glass & [38] \\
\hline \multicolumn{4}{|c|}{ Intrinsic defects - Electron center $(E C)$} \\
\hline $\mathrm{EC}$ & 302 & Soda lime glass & [21] \\
\hline \multirow[t]{2}{*}{ Si-EC1 } & 220 & BK7 & {$[40]$} \\
\hline & & DURAN & \\
\hline Si-EC2 & 245 & BK7 & {$[40]$} \\
\hline Si-EC3 & 305 & BK7 & {$[40]$} \\
\hline $\mathrm{E}^{\prime}$-center & 210 & Fused silica & [63] \\
\hline Peroxide & 163 & Fused silica & [62] \\
\hline \multirow[t]{2}{*}{ groups } & 230 & Soda lime glass & [21] \\
\hline & & sic defects & \\
\hline$\left(\mathrm{Ce}^{3+}\right)^{+}$ & 270 & Lithiumalumosilicate glass & [32] \\
\hline \multirow[t]{2}{*}{$\left(\mathrm{Ag}^{+}\right)^{-}$} & 340 & Lithiumalumosilicate glass & {$[30]$} \\
\hline & 450 & Methaphosphate glass & [34] \\
\hline$\left(\mathrm{Ag}^{+}\right)^{+}$ & 275 & Methaphosphate glass & [34] \\
\hline \multirow[t]{2}{*}{$\left(\mathrm{Sb}^{3+}\right)^{+}$} & 340 & Borosilicate glass & {$[36]$} \\
\hline & & lusters & \\
\hline$\left(\mathrm{Ag}^{+}\right)_{2}^{-}$ & 350 & Methaphosphate glass & [34] \\
\hline $\mathrm{Ag}_{3}^{+}, \mathrm{Ag}_{3}^{2+}$ & 280 & Soda lime glass & {$[21]$} \\
\hline \multirow[t]{3}{*}{ Ag cluster } & $350-550$ & Soda lime glass & {$[61]$} \\
\hline & 400 & Soda lime glass & {$[21]$} \\
\hline & $430-500$ & Soda lime glass & {$[62]$} \\
\hline
\end{tabular}




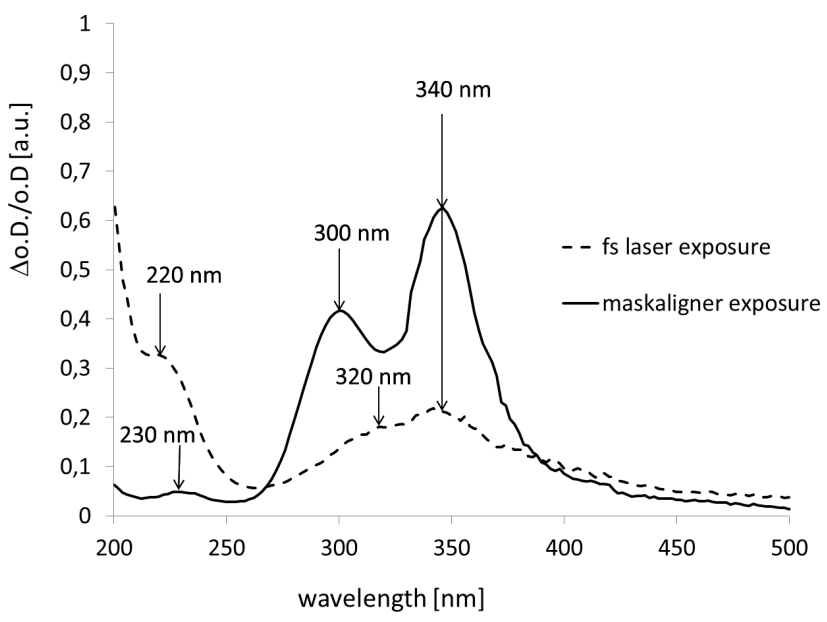

Figure 5: Change in optical density $\Delta$ o.D./o.D. $=$ (o.D. exposed $^{-}$ o.D. unexposed $/$ o.D. unexposed relative to the unexposed state of the photosensitive glass FS21 presented for a fs laser $\left(\epsilon=0.02 \mathrm{~J} / \mathrm{cm}^{2}\right.$, number of pulses $\mathrm{N}_{e f f}=230$ and a mask aligner exposure $(\epsilon=60$ $\left.\mathrm{J} / \mathrm{cm}^{2}\right)$.

charged electron centers (EC) like E'centers or peroxy radicals. Furthermore the ionisation of dopants like Ag and Ce is highly probable. We assume that the increased absorption at $\lambda<270 \mathrm{~nm}$ is an overlap of various radiation induced effects in FS21 resulting from bond breaking inside the base glass structure. It is obvious that intense fs laser radiation possesses a higher potential to affect the silicate structure than less intensive mask aligner exposure.

The increased absorption at $\lambda=340 \mathrm{~nm}$ is independent from possible superimpositions in the short wavelength range because of the sufficiently large distance to the absorption edge. It is very probable that this absorption can be related to $\mathrm{Ag}^{+}$ions that have trapped an electron $\left(\left(\mathrm{Ag}^{+}\right)^{-}\right)$[30]. Differences regarding the peak height between fs laser and mask aligner exposure can be explained by different radiation modified glass volumes. Overall heterogeneous nucleation involves silver clusters for both exposure methods. Different peak widths possibly result from further radiation induced effects with absorption bands near the visible wavelength range. We have found that the peak broadening is more pronounced for the fs laser exposure than for the mask aligner exposure. However, current research is focused to the investigation of absorption properties of diverse silver species in glass based on spectroscopic methods. Other studies reported on silver ion clusters in form of $\mathrm{Ag}_{m}^{n+}$ as a result of short pulse laser irradiation of glasses $[14,21,34,36]$. Correspondingly characteristic absorption bands exist in the wavelength range of $280 \mathrm{~nm} \leq \lambda \leq 380 \mathrm{~nm}$. The peak position strongly depends on the size of the ion cluster and the peak maximum is shifted to smaller wavelengths with increasing silver ion cluster size $\mathrm{m}$. Furthermore it seems to be probable that other effects play an important role as well. Leyderman $e t$ al. [37] describe alumina complexes that act as $\mathrm{HC}$ after irradiation, especially if either $\mathrm{Na}, \mathrm{Li}$ or $\mathrm{H}$ are part of the complex. Reference [38] states that these alumina related hole centers (Al-HC) cause an optical absorption at $\lambda=620$ $\mathrm{nm}$ in soda lime glass. Jani et al. [39] discuss silicon related hole center (Si-HC) in silica and single-crystal quartz after irradiation. Ehrt et al. [40] investigated radiation defects in boron silicate glasses and describe silicon related hole centers $\left(\mathrm{H}_{I}\right.$ and $\left.\mathrm{H}_{I I}\right)$ with optical absorptions at $\lambda=440$ $\mathrm{nm}$ and $\lambda=620 \mathrm{~nm}$. Möncke et al. [36] investigated the influence of radiation on $\mathrm{Sb}$ and $\mathrm{Sn}$ in a metaphosphate glass. They found an optical absorption at $\lambda=340 \mathrm{~nm}$ related to the photoionisation of $\mathrm{Sb}^{3+}$ to $\left(\mathrm{Sb}^{3+}\right)^{+}$. The radiation induced absorption related to the ionisation of Sn ions remains unclear. We conclude that in case of irradiation of FS21 with a UV lamp the dominant effect is the formation of $\left(\mathrm{Ag}^{+}\right)^{-}$. Additional to that, fs laser irradiation leads to an increased content of different HC, EC and photoionisation of the dopants. This fact can be justified by the increased absorption at the short and the long wavelength range in Figure 5.

\subsection{Differences in lithium metasilicate crystallisation between UV mask aligner and fs laser exposure}

UV mask aligner exposure of photosensitive glass FS21 leads to the crystallisation of lithium metasilicate. The applied one step thermal treatment program leads to a microstructure of the glass ceramic with single crystal sizes of $\sim 1 \mu \mathrm{m}$. Former investigations have shown that the crystal size can be influenced in two ways: (i) by variation of the energy density during UV exposure [41] and (ii) by variation of the time - temperature program during the thermal treatment [42]. Samples modified through the fs laser exposure process in this study show comparable single crystal sizes to those arising from the mask aligner exposure using comparable thermal conditions. According to $[43,44]$ it is expected that photosensitive glasses have an inhomogeneous structure on an atomic level characterised by fluctuations. Droplet-like phase segregation at the nanoscale dimension seems to be possible but has still not been proven up to now. Dopants tent to preferential concentration in such small areas. It was shown in [42] that silver nanoclusters with a critical nucleus radius exist with an even distribution. But not every environment of the silver clusters has a stoichiometric composition close to lithium metasilicate. As a result, not every silver cluster acts as hetero- 
geneous nucleus for the lithium metasilicate growth. We assume that UV radiation leads to photochemical modifications mainly of the dopant $\mathrm{Ce}^{3+}$ which is situated close to $\mathrm{Ag}^{+}$ions. In contrast to that, fs laser exposure changes the base glass without a notable participation of $\mathrm{Ce}^{3+}$ ions. It should be mentioned, that comparable results are described in [45]. Therefore we believe that the generation of diverse photoelectrons from the base glass matrix leads to a broader variety of silver ion clusters, in accordance with observations from Royon et al. [46]. It was reported that the development of silver ion clusters is coupled with the development of free radicals in the local environment. A strongly modified glassy structure is extremely probable.

We have found furthermore that fs laser exposed and crystallised samples show small bubbles within the microstructure in numerous cases using light microscopy. Big bubbles with sizes up to $50 \mu \mathrm{m}$ in diameter were observed in unexposed glass near the border to the crystallised areas. In the exposed and crystallised areas, very fine bubbles were distributed. Samples exposed using mask aligner have not shown this behaviour after thermal treatment. Figure 6 gives one example to visualize this phenomenon.

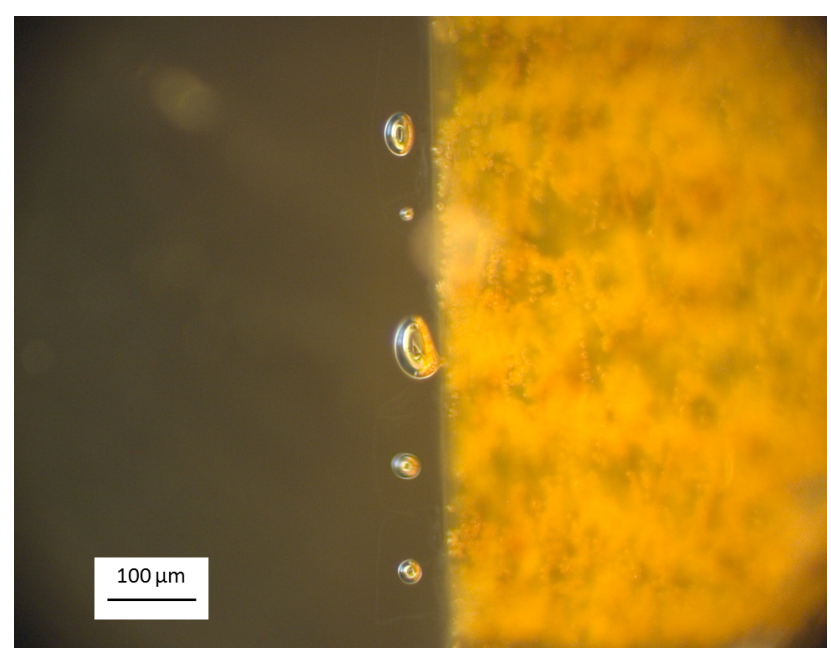

Figure 6: Light microscopy picture of a fs laser irradiated sample after thermal treatment. The left side is unexposed and therefore not crystallised, the right side is fs exposed and shows a brown coloured crystalline phase with small bubbles inside the glass. Big ger bubbles were found in the border range between the unexposed and exposed area.

For more insights the gas composition of one of the large bubbles was analysed by means of mass spectroscopy. The quantitative analysis is shown in Table 3 and was compared to normal air.
Table 3: Mass spectroscopy of the bubble content compared to relevant components in normal air [47].

\begin{tabular}{ccc}
\hline Component & $\begin{array}{c}\text { Bubble in glass } \\
\text { wt } \%\end{array}$ & $\begin{array}{c}\text { Air } \\
\text { wt } \%\end{array}$ \\
\hline $\mathrm{N}_{2}$ & $<48$ & 75 \\
$\mathrm{O}_{2}$ & $<12$ & 23 \\
$\mathrm{Ar}$ & - & 1.3 \\
$\mathrm{CO}_{2}$ & $<20$ & 0.06 \\
$\mathrm{CO}$ & $<13$ & $50-200 \mathrm{ppb}$ \\
$\mathrm{H}_{2} \mathrm{O}$ & 3.3 & dependent on weather \\
$\mathrm{H}_{2}$ & $<3 \%$ & $36 \mathrm{ppb}$ \\
\hline
\end{tabular}

Due to the fact that no Argon was found inside the investigated bubble, it is obvious that the ambient air is not the origin of the phase. These gaseous components (nitrogen, oxygen, carbon oxides, water and hydrogen) develop during processing and result from the glass composition itself. One reason could be an incomplete fining of the glass melt [48]. Residual contents can be physically dissolved or chemically bound inside the glass. Femtosecond laser irradiation in combination with a subsequent thermal treatment releases its reaction products (i) to a healing of defects in form of the recombination of EC and HC $[49,50]$, (ii) to the crystallisation of lithium metasilicate and (iii) to gas filled bubbles. Currently, the extent of the influence of the lithium metasilicate crystallisation on the defect recovery and the gas building process is not exactly clear due to the superimposition of these effects.

Short pulse laser radiation induced gas bubble building inside glasses is discussed by numerous authors as a direct result of the irradiation [51-56]. It is agreed that laser induced ionisation coupled with plasma induced thermal dissociation are responsible for the bubble building. The necessary chemical bond breaking is attributed to oxygen mono-vacancies (E'center), nonbridging-oxygen hole centers (NBOHC), peroxy radicals (PORs), aluminium-oxygen hole centre (Al-OHC) and other entities in vitreous $\mathrm{SiO}_{2}$ $[52,55,57,58]$. Table 2 gives an overview on optical absorption wavelength in different glasses. Furthermore molecular oxygen in fs laser induced gas bubbles was detected Raman spectroscopy in $\mathrm{GeO}_{2}$ glass [56]. In our case, it seems likely that radiolytic dissociation leads to a high number of different species with unpaired electrons that react with each other, forming gaseous molecules. Diffusion is enhanced under thermal treatment, together with volume change associated with crystallization, results in bubble formation. A local exchange of ions and molecules from unexposed neighbouring areas is probable due to the strong focus of fs laser radiation. Thermal diffusion 
processes seem to initiate not only the growth of lithium metasilicate crystals, but also to promote further the mobility and reboil of gaseous ingredients [59].

\subsection{Etch rate ratios}

The etch rate ratio quantifies the difference in solubility between the unexposed glass and the crystalline phase. It seems therefore obvious that this ratio determines significantly the resolution of geometries and has to achieve high values for complex micro geometries in fluidic applications. It is possible to quantify the etch rate ratio by measuring changes in relevant geometric dimensions of etched capillaries in photostructured glass components. The determination of the etch rate ratio was performed by means of the measured capillary geometries inside the glass, see Figure 7.

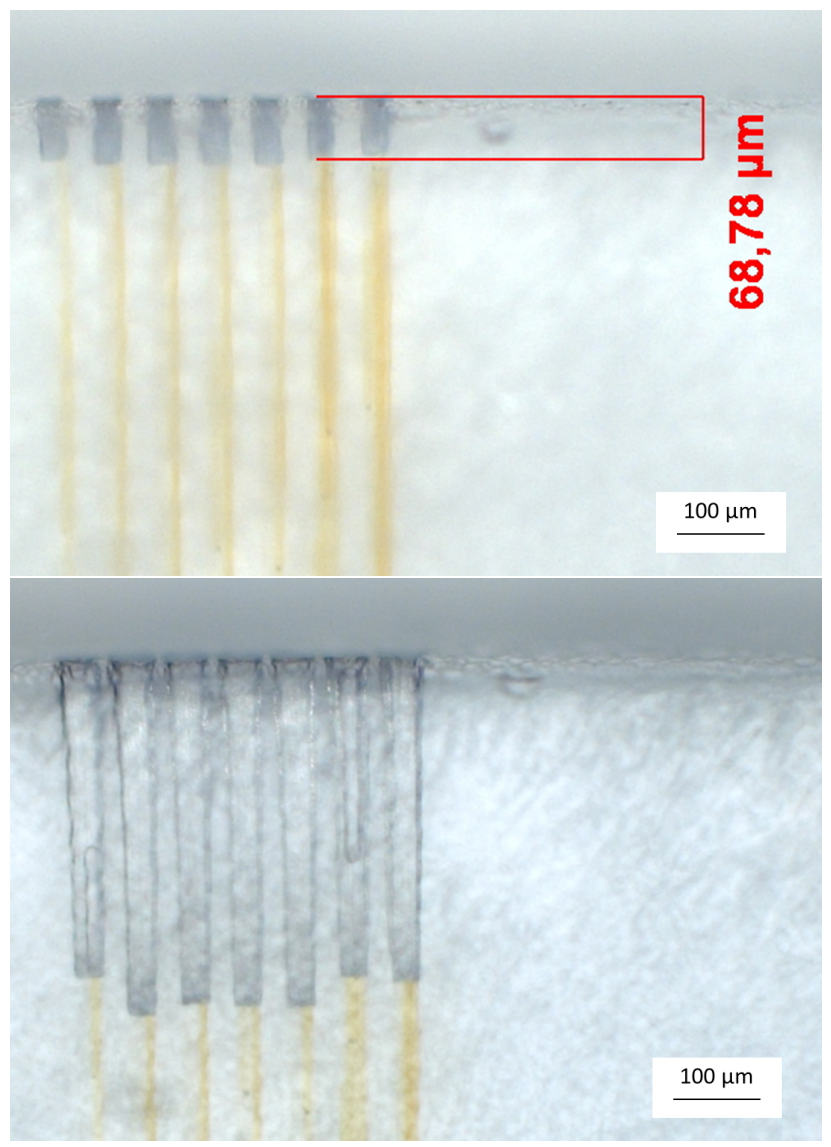

Figure 7: Etched geometry of subsurface channels (capillaries) inside the photosensitive glass FS21 after fs laser exposure, thermal treatment and wet chemical etching at two etching times $t_{\text {etch }}$, view from the topside of exposure, top: after $\mathrm{t}_{\text {etch }}=6 \mathrm{~min}$, bottom: after $\mathrm{t}_{\text {etch }}=36 \mathrm{~min}$.
According to [6] the etch rate ratio $\mathrm{R}_{\text {etch }}$ is defined as:

$$
R_{\text {etch }}=\frac{2 \cdot h_{\text {etch }}}{b_{\text {etch }}-b_{\text {crys }}}
$$

were $h_{\text {etch }}$ and $b_{\text {etch }}$ are the height and width of an etched capillary dependent on the etching time. $b_{\text {crys }}$ represent the width of the crystallised area of the subsurface channel after fs laser exposure and thermal treatment. The term $\left(b_{\text {etch }}-b_{\text {crys }}\right) / 2$ represents the opening of the capillaries and was determined together with the etch depth $h_{\text {etch }}$ for etching times between $1 \mathrm{~min} \leq t_{\text {etch }} \leq 36 \mathrm{~min}$. Figure 8 shows the calculated etch rate ratios.

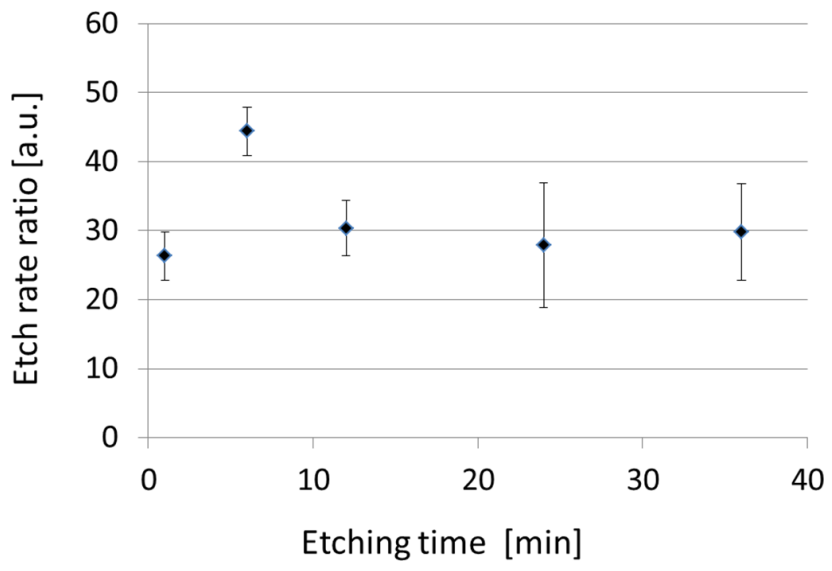

Figure 8: Etch rate ratio dependent on etching time for capillary geometries with a width $\mathrm{b}_{\text {crys }}=26 \mu \mathrm{m}$ of the crystalline area in photosensitive glass FS21.

It was found that the etch rate ratio is not constant over the entire etching time of $36 \mathrm{~min}$. The etch rate ratios show a clear variation with minimal values of 1:25 and maximal values of 1:45 and is influenced by three main points: (i) altered etching conditions at the surface, (ii) etchant exchange inside the capillary during the ultrasonic supported etching process and (iii) the crystal size and the crosslinking of the crystals. At the beginning the etch rate ratio is reduced to only 1:25. Due to variations of the stoichiometric composition near the surface, the degree of crystallization is reduced in contrast to the lower volume areas. The etch rate ratio is increased to 1:45 for etching times between $1 \mathrm{~min} \leq t_{\text {etch }} \leq 6 \mathrm{~min}$. After $\mathrm{t}=6 \mathrm{~min}$ the etch depth amounts to $69 \mu \mathrm{m}$. Inside this area, the degree of crystallization, as well as the small capillary depth coupled with a good exchange of the etchant, result in a temporary maximum in the etch rate ratio. For capillary depth of $69 \mu \mathrm{m} \leq h_{\text {etch }} \leq 350 \mu \mathrm{m}$ a mean value of 1:30 was found. It should be noted, that this value corresponds well with the etch rate ratio obtained from our photoform process, 
which was based on a mask aligner exposure. The measured angles $\alpha$ of the side wall $\alpha$ amounts between $1.2^{\circ}$ $\leq \alpha \leq 2.0^{\circ}$. Furthermore, the etch rate ratio scattered in creasingly for long etching times. This fact corresponds to a strong scattering of the large etch depths at these etching times. Different capillary actions influence the etchant exchange with different degrees.

\section{Conclusion and outlook}

We investigated a photosensitive lithiumalumosilicate glass FS21 doped with $\mathrm{CeO}_{2}, \mathrm{Ag}_{2} \mathrm{O}, \mathrm{SnO}, \mathrm{Sb}_{3} \mathrm{O}_{5}$ regarding the sensitivity to fs laser radiation in comparison to UV lamp exposure in a mask aligner. FS laser radiation leads to several defects accompanied by the generation of photoelectrons, from photooxidation of polyvalent ions, but mainly from holecenters that were formed in the base glass. Photosensitivity was found to set in above a low critical dose of $D_{c}=7.6 \cdot 10^{-6}\left(\mathrm{~J} / \mathrm{cm}^{2}\right)^{4}$. It means that in minimum four photons are involved in the complex absorption process which leads to a modification of FS21, followed by nucleation and growth of lithium metasilicate crystals during the subsequent thermal treatment and finally in etched pits after wet chemical etching with $5 \%$ hydrofluoric acid. The glass structure has been shown to be decisive for any photo induced defect formation, not only in regard to the base composition but also in respect to the presence of dopants or impurities. Many of the given references gave evidence for that. The access to information about the absorption centres is hardly possible due to a complex glass structure comprising of nine components added either as carbonates, nitrates or oxides as raw materials that lead to a large scale of overlapping effects using UV-VIS spectral photometry. A comparison of chemical compositions between FS21 and Foturan [60] shows the difference regarding the content of glass network modifying components like alkali, intermediates like alumina as well dopants.

We have shown by means of spectrophotometric researches the formation of $\left(\mathrm{Ag}^{+}\right)^{-}$[30] as a result of irradiation with UV light or fs laser radiation. The latter results in a peak broadening around $\lambda=340 \mathrm{~nm}$. We assume an association with the formation of other silver species like $\mathrm{Ag}_{m}^{n+}$ or intrinsic and extrinsic defects according to Table 2. The diversity of radiation induced species seems to be somewhat higher for the fs laser exposure than for the mask aligner exposure.

It is remarkable that fs laser irradiated samples show bubble formation after thermal treatment, which was only intended to accompany crystal growth in the photo- exposed areas, but not directly after laser or UV-treatment. The gaseous content comprises most probably residuals from the raw materials which remained during the fining of the glass melt. This effect shows the capacity of the glass to solve small amounts of carbonates, nitrates and water within its structure. Currently the average etch rate ratio for geometrical structures is around 1:30 for depths of $>10$ $\mu \mathrm{m}$, mainly influenced by the exchange of the etchant fluid. Subsurface channels with a width of $<30 \mu \mathrm{m}$ are accessible. The complexity of subsurface microstructured geometries is limited by the etching solvents transport due to capillary force. It has to be examined in further studies to what extent a nano-porous crystallised phase can influence the corresponding etch rate ratio.

With the perspective of biomedical applications the glass composition plays an important role. The used photosensitive lithiumalumosilicate glass is located in the primary precipitation field of lithium metasilicate. A temperature of $\mathrm{T}=600^{\circ} \mathrm{C}$ is needed for homogeneous nucleation and growth of lithium metasilicate [42]. Photosensitive additives in form of $\mathrm{Ag}_{2} \mathrm{O}, \mathrm{CeO}_{2}, \mathrm{SnO}$ and $\mathrm{Sb}_{3} \mathrm{O}_{5}$ allow heterogeneous nucleation at a lower temperature of $\mathrm{T}=450^{\circ} \mathrm{C}$. With these additives the thermal induced crystallisation takes place only in irradiated areas. The microstructure of the glass will be preserved as far as the growth of silver nuclei and of lithium metasilicate will not be suppressed by the crystallisation process in the case of fs laser exposure. All photosensitive dopants in the glass are oxidic. They are inoffensive from the view of biomedical applications. Silver particles of $7 \mathrm{~nm}$ size are formed as a result of irradiation and thermal treatment. They are part of the crystallised areas and will be removed together with lithium metasilicate during the wet chemical etching. First tests have shown the good biocompatibility of photosensitive glass surfaces. A proliferation of mouse fibroblasts shows a cell vitality of more than $93 \%$. This result is very promising. However, typical bio glasses try to avoid aluminium in their glass composition. This fact will be investigated by studying bio glass compositions versus microstructured photosensitive glasses in our further research. Furthermore the role of dopants in a fs laser exposure process has to be investigated with the clear objective to optimize the photosensitive glass composition.

Acknowledgement: This work is part of a research program funded by the German Research Foundation (DFG) (projects RA 706/8-1 and LI 916/11-1). 


\section{References}

[1] Sugioka K., Masuda M., Hongo T., Cheng Y., Shihoyama K., Midorikawa K., Three-dimensional microfluidic structure embedded in photostructurable glass by femtosecond laser for lab-on-chip applications, Appl. Phys. A, 2004, 79, 815-817

[2] He F., Sun H., Huang M., Xu J., Liao Y., Zhou Z., Cheng Y., et al., Rapid fabrication of optical volume gratings in Foturan glass by femtosecond laser micromachining, App. Phys. A, 2009, 97, 853-857

[3] Williams J. D., Schmidt C., Serkland D., Processing advances in transparent Foturan ${ }^{\circledR}$, MEMS. Appl. Phys. A, 2010, 99, 777-782

[4] Wu D., Xu J., Niu L.-G., Wu S.-Z., Midorikawa K., Sugioka K., Inchannel integration of designable microoptical devices using flat scaffold-supported femtosecond-laser microfabrication for coupling-free optofluidic cell counting, Light: Science \& App., 2015, 4, e228, 1-8

[5] Khan Malek Ch.G., Laser processing for bio-microfluidics applications (part I), Anal Bioanal Chem (2006) 385: 1351-1361 DOI 10.1007/s00216-006-0514-2

[6] Serien D., Kawano H., Miyawaki A., Midorikawa K., Sugioka K., Femtosecond Laser Direct Write Integration of Multi-Protein Patterns and 3D Microstructures into 3D Glass Microfluidic Devices, Applied Sciences 2018, 8(2), 147, doi:10.3390/app8020147

[7] Brokmann U., Jacquorie M., Talkenberg M., Harnisch A., Kreutz E.-W., Hülsenberg D., Poprawe R., Exposure of photosensitive glasses with pulsed UV-laser radiation, Microsys. Technol. 8, 102 - 104, Springer-Verlag 2002, DOI 10.1007/s00542-001-0134-x

[8] Mrotzek S., Harnisch, A., Hülsenberg D., Brokmann U.: Crystallisation mechanism in ultraviolet sensitive microstructurable glasses, Proc. VII Symp. On Crystallisation in Glasses and Liquids, Sheffield, 6-9 July 2003, Glass Technol., 2004, 45, 97-100

[9] Hülsenberg D., Harnisch A., Bismarck A., Microstructuring of glasses, Springer-Verlag Berlin Heidelberg, 2008

[10] Evans A., Rupp J. L. M., Gauckler L. J., Crystallisation of Foturan glass-ceramics. J. of Europ. Ceram. Soc., 2012, 32, 203 -210

[11] Sugioka K., Cheng Y., Fabrication of 3 D microfluidic structures inside glass by femtosecond laser micromachining, Appl. Phys. A, 2014, 114, 215-221

[12] Honma T., Nguyen P.T., Komatsu T., Crystal growth behavior in CuO-doped lithium disilicate glasses by continuous-wave fiber laser irradiation, J. Ceram. Soc. Jpn., 116 (2008) 1314-1318. http://dx.doi.org/10.2109/jcersj2.116.1314

[13] Griscom D.L., Electron spin resonance in glasses, J. Non-Cryst. Solids, 40 (1980) 211-272. http://dx.doi.org/10.1016/00223093(80)90105-2

[14] Bellec M., Royon A., Bousquet B., Bourhis K., Treguer M., Cardinal T., et al., Beat the diffraction limit in 3D direct laser writing in photosensitive glass, OPTICS EXPRESS, 06/2009, Vol. 17, No. 12, 10304-10318

[15] Glebov L., Glebova L., Rotari E., Gusarov A., Berghmans F., Radiation-induced absorption in a photo-thermo-refractive glass, Proc. SPIE 5897, Photonics for Space Environments X, 58970) (18 August 2005), doi: 10.1117/12.619206

[16] Kim J., Berberoglu H., Xu X., Fabrication of microstructures in photoetchable glass ceramics using excimer and femtosecond lasers, Society of photo-optical instrumentation engineers, July $2004,478-485$
[17] Fisette B., Busque F., Degorce J.-Y., Meunier M.: Threedimensional crystallisation inside photosensitive glasses by focused femtosecond laser. Appl. Phys. Lett., 2006, 88, 091104(1) - 091104(3)

[18] Kondo Y., Qiu J., Mitsuyu T., Hirao K., Yoko T., Three-Dimensional Microdrilling of Glass by Multiphoton Process and Chemical Etching, Jpn. J. Appl. Phys., 1999, 38, 1146-1148

[19] Tomozawa M., Doremus R. H., Glas I: Interaction with electromagnetic radiation, In Treatise on materials science and technology, Vol. 12, Academic Press New York, San Francisco, London, 1977

[20] Ehrt D., Photoactive glasses and glass ceramics, Int. Symposium on Global Multidisciplinary Engineering (24-25 Jan 2011, Nagaoka Univ. of Tech., JAP), IOP Conf. Series: Materials Science and Engineering 21 (2011) 012001

[21] Espiau de Lamaestre R., Bea H., Bernas H., Belloni J., Marinier J. L.: Irradiation induced $\mathrm{Ag}$ nanocluster nucleation in silicate glasses: Analogy with photography, Phys. Rev. B, 2007, 76, 205431(1) 205431(18)

[22] Schütz A., Ehrt D., Dubiel M., Yang X.C., Mosel B., Eckert H., A multi-method characterization of borosilicate glasses doped with 1 up to 10 mol\% of Fe, Ti and Sb, Glass Sci. Technol., 77 (2004) 295-305.

[23] Ehrt D., Redox behaviour of polyvalent ions in the ppm range, J. Non-Cryst. Solids, 196 (1996) 304-308. Doi: 10.1016/00223093(95)00604-4

[24] Fuqua P.D., Taylor D.P., Helvajian H., Hansen W.W. and Abraham M.H., A UV direct-write approach for formation of embedded structures in photostructurable glass-ceramics, Mater. Res. Soc. Symp. Proc., 2000, 624, 79-86

[25] Juodkazis S., Yamasaki K., Mizeikis V., Matsuo S., Misawa H., Formation of embedded patterns in glasses using femtosecond irradiation, Appl. Phys. A, 2004,79, 1549-1553

[26] Fernandez-Pradas J.M., Serrano D., Morenza J. L., Serra P., Microchannel formation through Foturan $®$ with infrared femtosecond and ultraviolet nanosecond lasers, J. Micromech. Microeng., 2011,21, 025005

[27] Masuda M., Sugioka K., Cheng Y., Aoki N., Kawachi M., Shihoyama K., 3-D microstructuring inside photosensitive glass by femto-second laser excitation, Appl. Phys. A, 2003, 76, 857-860

[28] Kortüm G., Reflexionsspektroskopie, Springer Verlag BerlinHeidelberg, 1969

[29] Möncke D., Ehrt D., Radiation-induced defects in CoO- and NiOdoped fluoridephosphate glasses, Glastech. Ber. Glass Sci. Technol. 74 (2001) No. 3

[30] Korn H., Hinz W., Fotochemische Reaktionen im LithiumAluminium-Silikatglas, Silikattechnik, 1972, 23 (3), 80 - 83

[31] Glebova L., Ehrt D., Glebov L., Luminescence of doptants in PTR glass, Phys. Chem. Glasses, Eur. J. Glass Sci. Technol. B, 2007, 48 (5), 328-331

[32] Stroud J. S., Photoionisation of $\mathrm{Ce}^{3+}$ in Glass, The Journal of Chemical Physics, 1961, 35 (3), $844-850$

[33] Bach H., Neuroth N. (Eds.), The Properties of Optical Glass, Springer Verlag Berlin-Heidelberg, 1998

[34] Möncke D., Ehrt D., Photoionisation of polyvalent ions, Materials Science Research Horizons, Nova Science Publishers Inc., 2007, 1-56

[35] Ehrt D., Ebeling P., Natura U., Kolberg U., Naumann K., Ritter S., Redox equilibrium and ultraviolet radiation induced defects in glasses, Proc. Int. Cong. on Glass, (1-6- July 2001, Edinburgh, 
Scotland), Vol. 1, 84-93

[36] Möncke D., Ehrt D., Photoionisation of As, Sb, Sn and Pb in metaphosphate glasses, J. of Non-Crystalline Solids, 2004, Vol. $345-346,319-322$

[37] Leyderman A., Weil J.A., Williams J.A.S., Generation of paramagnetic centers in crystalline quarz by ultraviolet irradiation, J. Phys. Chem. Solids, Vol. 46, No.4 (1985), pp. 519-522

[38] Ezz-Eldin F.M., Mahmoud H.H., Abd-Elaziz T.D., El-Alaily N.A., Response of commercial window glass to gamma doses, Physica B 403 (2008) 576-585

[39] Jani M.G., Halliburton L.E., Halperin A., Observation of a simple lithium-associated electron trap in crystalline $\mathrm{SiO}_{2}$, Phy. Rev. Lett., Vol. 56, No. 13 (1986), pp. $1392-1395$

[40] Ehrt D., Ebeling P., Radiation defects in borosilicate glasses, Glass Technol., 44 (2003) 46-49

[41] Brokmann U., Harnisch A., Ertel-Ingrisch W., Hülsenberg D., UV laser radiation for microstructuring of photostructurable glasses, Glass Sci. Technol., 2004, 77 (5), 249-252

[42] Mrotzek S., Kristallisation eines UV-strukturierbaren Glases im System $\mathrm{Li}_{2} \mathrm{O}-\mathrm{Al}_{2} \mathrm{O}_{3}-\mathrm{SiO}_{2}$. PhD thesis, Technische Universtität Ilmenau, Germany, 2005

[43] Vogel W., Glass chemistry, Springer Verlag Berlin-Heidelberg, 1994

[44] Pavluškin N.M., Vitrokeramik, VEB Deutscher Verlag für Grundstoffindustrie, Leipzig 1986

[45] Hongo T., Sugioka K., Investigation of photoreaction mechanism of photosensitive glass by femtosecond laser, J. Appl. Phy., 2005, 97, 063517

[46] Royen A., Petit Y., Papon G., Richardson M., Canioni L., Femtosecond laser induced photochemistry in materials tailored with photosensitive agents, Optical materials express, 08/2011, Vol. 1, No. 5, $866-882$

[47] https://de.wikipedia.org/wiki/Luft, 27.11.2018

[48] Shelby J.E., Introduction to Glass Science and Technology, The Royal Society of Chemistry, Cambridge, 1997

[49] Natura U., Ehrt D., Generation and healing behavior of radiationinduced optical absorption in fluoride phosphate glasses: The dependence on UV radiation sources and temperature, $\mathrm{Nu}$ clear Instruments \& Methods in Physics Research Section BBeam Interactions with Materials and Atoms, 174 (2001) 143-150. http://dx.doi.org/10.1016/s0168-583x(00)00449-3

[50] Natura U., Ehrt D., Modeling of excimer laser radiation induced defect generation in fluoride phosphate glasses, Nuclear Instruments \& Methods in Physics Research Section BBeam Interactions with Materials and Atoms, 174 (2001) 151-158. http://dx.doi.org/10.1016/s0168-583x(00)00450-x
[51] Bellouard Y., Hongler M.-O., Femtosecond-laser generation of self-organized bubble patterns in fused silica, Opt. Express, 19 (2011) 6807-6821, http://dx.doi.org/10.1364/OE.19.006807

[52] Cvecek K., Miyamoto I., Schmidt M., Gas bubble formation in fused silica generated by ultra-short laser pulses, Opt. Express, 22 (2014) 15877-15893, http://dx.doi.org/10.1364/OE.22.015877

[53] Luo F., Lin G., Sun H., Zhang G., Liu L., Chen D., Chen Q., Zhao Q., Qiu J., Xu Z., Generation of bubbles in glass by a femtosecond laser, Opt. Commun., 284 (2011) 4592-4595. https://doi.org/10.1016/j.optcom.2011.05.060

[54] Watanabe W., Itoh K., Motion of bubble in solid by femtosecond laser pulses, Opt. Express, 10 (2002) 603-608, http://dx.doi.org/10.1364/OE.10.000603

[55] Efthimiopoulos I., Palles D., Richter B., Hoppe U., Möncke D., Wondraczek L., Nolte S., Kamitsos E.I., Femtosecond laser-induced transformations in ultra-low expansion glass: Microstructure and local density variations by vibrational spectroscopy, Journal of Applied Physics, 123 (2018), 233105.10.1063/1.5030687

[56] Bressel L., de Ligny D., Gamaly E.G., Rode A.V., Juodkazis S., Observation of $\mathrm{O}_{2}$ inside voids formed in $\mathrm{GeO}_{2}$ glass by tightlyfocused fs-laser pulses, Optical Materials Express, 1 (2011) 11501158, http://dx.doi.org/10.1364/OME.1.001150

[57] Griscom D.L., A minireview of the natures of radiation-induced point defects in pure and doped silica glasses and their visible/near-IR absorption bands, with emphasis on self-trapped holes and how they can be controlled, Hindawi Publishing Corporation Physics Research International, Vol. 2013, Article ID 379041, 14 pages

[58] Ebeling P., Ehrt D., Friedrich M., Radiation-induced color centers in anion doped phosphate glasses Phosphorus Research Bulletin, 10 (1999) pp.484-489, http://dx.doi.org/10.3363/ prb1992.10.0_484

[59] Jebsen-Marwedel H., Brückner R., Glastechnische Fabrikationsfehler, Springer Verlag Berlin Heidelberg, 2011

[60] Schott/IMM information, FOTURAN - a material for microtechnology, 1994

[61] M. Dubiel, Schneider R., Hofmeister H., Schicke K.-D., Pivin J. C., Formation of argentic clusters and small Ag nanoparticles in soda-lime silicate glass. Eur. Phys. J. D, 2007, 43, 291-294

[62] Stepanov A.L., Hole D.E., Townsend P.D., Modification of size distribution of ion implanted silver nanoparticles in sodium silicate glass using laser and thermal annealing, Nuclear Instruments and Methods in Physics Research B, 1999, 149, 89-98

[63] Escher G. C., KrF laser induces color centers in commercial fused silica, SPIE Proceedings, (O-E/Fiber LASE '88, 1988, Boston, MA, United States), 998, 30-37 